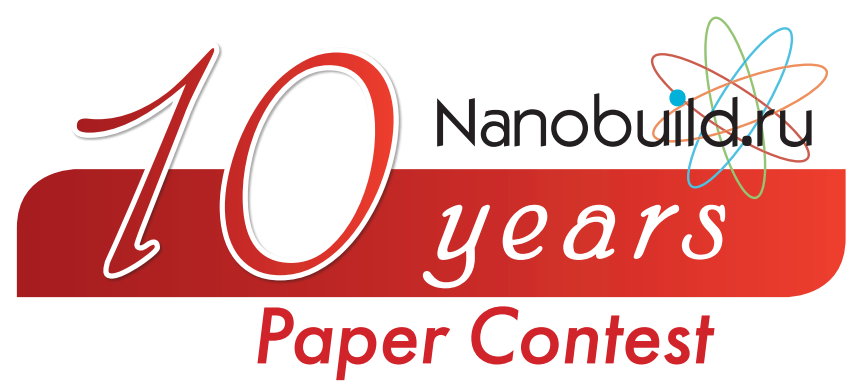

UDC 622.244.4

Author: ARTAMONOV Vadim Yurevich, Ph.D, Senior Researcher, Mechanical Engineering Research Institute of the Russian Academy of Sciences; Bardina St., 4, Moscow, 11933, e-mail: vartamonov@bk.ru;

Author: GANIEV Stanislav Rivnerovich, Ph.D, Leading Researcher, Mechanical Engineering Research Institute of the Russian Academy of Sciences; Bardina St., 4, Moscow, 11933;

Author: ISMAKOV Rustem Adipovich, Professor, Doctor of Engineering, Full member (Academician) of the Russian Academy of Natural Sciences, Honored Oil Worker, Honorary Worker of Higher Professional Education of the Russian Federation, Vice-Rector for Scientific and Innovative Work, Ufa State Oil Technical University; Kosmonavtov Str., 1, Ufa, 450062;

Author: KUZNETSOV Yuri Stepanovich, Professor, Doctor of Engineering, Deputy Director of Science, Mechanical Engineering Research Institute of the Russian Academy of Sciences; Bardina St., 4, Moscow, 11933;

Author: PUSTOVGAR Andrey Petrovich, Ph.D, Leading Researcher, Mechanical Engineering Research Institute of the Russian Academy of Sciences; Bardina St., 4, Moscow, 11933;

Author: SULTANOV Danir Rizifovich, Ph.D, Researcher, Mechanical Engineering Research Institute of the Russian Academy of Sciences; Bardina St., 4, Moscow, 11933,

e-mail: sultanov.d.r@yandex.ru;

Author: SHMIRKOV Oleg Vladimirovich, Ph.D, Head of Laboratory, Mechanical Engineering Research Institute of the Russian Academy of Sciences; Bardina St., 4, Moscow, 11933

\title{
EXPERIMENTAL STUDIES OF WAVE ACTION ON THE SUSPENSION OF MONTMORILLONITE CLAY
}

\section{ExTended Abstract:}

The paper presents the results of complex studies of influence of wave technologies on physical and mechanical properties of fine-dispersed montmorillonite suspensions in laboratory conditions at Research Center for Nonlinear Wave Mechanics and Technology Mechanical Engineering Research Institute of the Russian Academy of Sciences. It is shown that wave processing by means of hydrodynamic flow type generators with tangential and radial channels and flattype generators with cylindrical bodies of flow resulted in substantially increased 
dynamic shear stress, the number of particles in the 1-2 $\mu \mathrm{m}$ solution has grown 2.5 times. This means that the wave processing of the clay suspension leads to increasing of the colloid fraction, and, consequently, to improvement of the suspension quality, to decrease in the clay powder consumption, and also to several times reduced preparing time, compared to conventional technology. It is demonstrated that the main contribution to achieve high efficiency of wave processing is made by nonlinear wave and cavitation processes that run in the flowing part of hydrodynamic generators.

Key words: montmorillonite, clay suspension, wave technologies, wave field, reservoir filtration and reservoir properties, bottom-hole formation zone, filtration rate.

DOI: dx.doi.org/10.15828/2075-8545-2018-10-4-166-180

MACHINE-READABLE INFORMATION ON CC-LICENSES (HTML-CODE) IN METADATA OF THE PAPER

$<$ a rel="license" href="http://creativecommons.org/licenses/by/4.0/" $><$ img alt="Creative Commons License" style="borderwidth:0" src="https://i.creativecommons.org/l/by/4.0/88x31.png" / ></a $><$ br $/><$ span xmlns:dct="http://purl.org/dc/ terms/" href="http://purl.org/dc/dcmitype/Text" property="dct:title" rel="dct:type" $>$ Experimental studies of wave action on the suspension of montmorillonite clay $</$ span $>$ by $<$ a xmlns:cc="http://creativecommons.org/ns\#" href="Nanotehnologii v stroitel'stve $=$ Nanotechnologies in Construction. 2018, Vol. 10, no. 4, pp. 166-180. DOI: dx.doi.org/10.15828/2075- 85452018-10-4-166-180" property="cc:attributionName" rel="cc:attributionURL">Artamonov V.Yu., Ganiev S.R., Ismakov R.A., Kuznetsov Yu.S., Pustovgar A.P., Sultanov D.R., Shmirkov O.V. $</ a>$ is licensed under a $<$ a rel="license" href="http:// creativecommons.org/licenses/by $/ 4.0 / ">$ Creative Commons Attribution 4.0 International License $</ \mathrm{a}>.<\mathrm{br} />$ Based on a work at <a xmlns:dct="http://purl.org/dc/terms/" href=" http://nanobuild.ru/en_EN/nanobuild-4-2018/" rel="dct:source" $>$

http://nanobuild.ru/en_EN/nanobuild-4-2018/</a $>$. $<$ br $/>$ Permissions beyond the scope of this license may be available at $<$ a xmlns:cc="http://creativecommons.org/ns\#" href="vartamonov@bk.ru"rel="cc:morePermissions">vartamonov@bk.ru</ $\mathrm{a}>$.

\section{References:}

1. Gaydarov M. M-r., Kravtsov S.A. Dezintegratornaya tekhnologiya prigotovleniya burovykh rastvorov i tekhnologicheskikh zhidkostey [Disintegrator technology of drilling fluids and process fluids preparation]. Stroitel'stvo neftyanykh i gazovykh skvazhin na sushe i na more [Construction of oil and gas wells ashore and afloat]. № 10. 2007. P. 2933.(In Russian).

2. Ganiyev R.F. Volnovyye mashiny i tekhnologii (vvedeniye v volnovuyu tekhnologiyu) [Wave machines and technologies (introduction to wave technology)]. Moscow. Publishing Center RHD [Regular and Chaotic Dynamics]. 2008. 192 p. (In Russian).

3. Ganiyev R.F., Ukrainskiy L.Ye. Nelineynaya volnovaya mekhanika i tekhnologii [Nonlinear wave mechanics and technologies]. Moscow. Publishing Center RHD [Regular and Chaotic Dynamics]. 2008. 712 p. (In Russian). 
4. Ganiyev R.F. Nelineynyye rezonansy i katastrofy. Nadezhnost', bezopasnost' i besshumnost' [Nonlinear resonances and catastrophes. Reliability, safety and quietness]. Moscow. Publishing Center RHD [Regular and Chaotic Dynamics]. 2013. 592 p. (In Russian).

5. Artamonov V.Yu., Ganiyev S.R., Kuznetsov Yu.S., Pustovgar A.P., Sultanov D.R., Shmyrkov O.V. Volnovaya obrabotka maloglinistykh suspenziy [Wave treatment of thin-clay suspensions]. Kolebaniya i volny v mekhanicheskikh sistemakh: Materialy Mezhdunarodnoy nauchnoy konferentsii [Oscillations and waves in mechanical systems: Materials of the International Scientific Conference]. 2017. P. 56-57. (In Russian).

6. Artamonov V.Yu., Arzhanov A.F., Kuznetsov Yu.S., Kuznetsov R.Yu., Sultanov D.R., Shul'gina A.P. Tekhnologiya "shchadyashchey» kol'matatsii v protsesse bureniya [The technology of «gentle» colmatage during the drilling process]. Kolebaniya i volny v mekhanicheskikh sistemakh: Materialy Mezhdunarodnoy nauchnoy konferentsii [Oscillations and waves in mechanical systems: Materials of the International Scientific Conference]. 2017. P. 61-63. (In Russian).

7. Urmancheyev V.I., Ovchinnikov V.P., Ganiyev S.R., Kuznetsov Yu.S., Sultanov D.R., Shakirov R.A. Primeneniye dezintegratornoy tekhnologii [Application of the desintegrator technology]. Kolebaniya i volny v mekhanicheskikh sistemakh: Materialy Mezhdunarodnoy nauchnoy konferentsii [Oscillations and waves in mechanical systems: Materials of the International Scientific Conference]. 2017. P. 79-80. (In Russian).

8. Artamonov V.Yu., Pustovgar A.P., Sultanov D.R., Koshelev A.T., Kuznetsov Yu.S., Ganiyev S.R. Volnovaya tekhnologiya prigotovleniya burovoy promyvochnoy zhidkosti [Wave technology for preparation of drilling washing liquids]. Stroitel'stvo neftyanykh i gazovykh skvazhin na sushe i na more [Construction of oil and gas wells ashore and afloat]. 2017. № 11. P. 31-34. (In Russian).

9. Artamonov V.Yu., Shamov N.A., Sultanov D.R. Ispol'zovaniye volnovykh protsessov v obrabotke mnogofaznykh rastvorov [The use of wave processes in the processing of multiphase solutions]. Mashiny, tekhnologii i materialy dlya sovremennogo mashinostroyeniya: Sbornik tezisov dokladov mezhdunarodnoy nauchnoy konferentsii [Machines, technologies and materials for modern machine building: Proceedings of the international scientific conference]. 2013. P. 142. (In Russian).

10. Rakhmatullina G.V., Asfandiyarov L.Kh., Ismakov R.A., Nigmatullin V.R., Nigmatullin I.R., Rakhmatullin V.R., Zalyayev O.A. Izucheniye granichnykh smazochnykh sloyev burovykh promyvochnykh sred [Study of boundary lubricating layers of drilling muds]. Tribologiya i nadezhnost': Sbornik trudov XIII Mezhdunarodnoy nauchnoy konferentsii [Tribology and Reliability: Proceedings of the XIII International Scientific Conference]. 2013. P. 110-112. (In Russian).

11. Ismakov R.A., Mamayeva O.G., Konesev V.G., Vyaznikovtsev S.F., Matyushin V.P., Konesev G.V. Issledovaniye kineticheskikh i korkoobrazuyushchikh svoystv rastvorov dlya bureniya skvazhin pri stroitel'stve truboprovodov i razrabotke mestorozhdeniy uglevodorodov [Investigation of kinetic and plastering properties of drilling fluids for pipeline development and development of hydrocarbon's fields]. Neftegazovoye delo [Oil and Gas Business]. 2011. № 6. P. 82-89. (In Russian).

12. Abrams A. Mud design to minimize rock impairment due to particle invasion. - J. Petr. Techn., may 1977, vol. 29, № 5, pp. 586-592. 
13. Artamonov V.Yu. Razrabotka fiziko-khimicheskikh metodov kol'matatsii kollektorov dlya povysheniya kachestva ikh vskrytiya: Dissert. na soiskaniye uchenoy stepeni kandidata tekhn. Nauk [Development of physicochemical methods of colmatation of reservoirs for improving the quality of their dissection: Ph.D. thesis]. Tyumen', Tyumenskiy gosudarstvennyy neftegazovyy universitet [Tyumen State Oil and Gas University], 2001. 167 p. (In Russian).

14. Ovchinnikov V.P., Agzamov F.A., Akbulatov T.O., Aksenova N.A., Anashkina A.Ye., Gerasimov D.S., Grechin Ye.G., Grosheva T.V., Dvoynikov M.V., Zakirov N.N., Ismakov R.A., Kleshchenko I.I., Konesev G.V., Kuznetsov V.G., Kulyabin G.A., Kurbanov Ya.M., Kustyshev A.V., Levinson L.M., Makovskiy Yu.S., Ovchinnikov P.V.et al. Tekhnologiya bureniya neftyanykh i gazovykh skvazhin. Uchebnik dlya studentov vuzov: v 5 tomakh [Technology of drilling oil and gas wells. Textbook for university students in 5 volumes]. Tyumen', 2017.

15. Makarova I.I. Issledovaniye i razrabotka tekhnologiy, obespechivayushchikh sokhraneniye prirodnoy pronitsayemosti produktivnykh plastov: Dissert. na soiskaniye uchenoy stepeni kandidatov tekhn. nauk [Research and development of technologies that ensure the conservation of natural permeability of reservoirs: the thesis for obtaining the scientific degree of Candidate of Technical Sciences]. Moskva, Rossiyskaya Akademiya Nauk [The Russian Academy of Sciences], 2013, 148 p. (In Russian).

16. Ignat'yev A.V., Kuznetsov Yu.S., Ukrainskiy L.Ye. Teoreticheskiye aspekty ispol'zovaniya yavleniya gruppirovaniya chastits v volnovom pole dlya kol'matatsii poristykh sred [Theoretical aspects of using particles grouping effect in wavefield for mudding in pore space]. Neftegazovoye delo [Oil and Gas Business], 2010, № 2. Available at http://www.ogbus. $\mathrm{ru}$ /authors/Ignatiev/Ignatiev_1.pdf (Accessed 10.08.2018).

17. Korotayev Yu.P., Shvidler M.I. Raschet proniknoveniya glinistogo rastvora v plast [Calculation of the penetration of clay solution into the formation]. Gazovaya promyshlennost' [GAS Industry of Russia], 1971. № 8, P. 1-2. (In Russian).

18. Polyakov V.N., Vyakhirev V.I., Ippolitov V.V. Sistemnyye resheniya tekhnologicheskikh problem stroitel'stva skvazhin [System solutions for technological problems of well construction]. Moscow. Nedra-Biznestsentr, 2003. 240 p. (In Russian).

19. Chernykh V.A. Gidromekhanika neftegazodobychi [Hydromechanics of oil and gas production]. Moscow. VNIIGAZ, 2001. 277 p. (In Russian).

20. Shekhtman Yu.M. Fil'tratsiya malokontsentrirovannykh suspenziy [Filtration of lowconcentration suspensions]. Moscow. Academy of Sciences of the USSR, 1961. 212 p. (In Russian).

\section{DEAR COLleAgues!}

THE REFERENCE TO THIS PAPER HAS THE FOLLOWING CITATION FORMAT:

Artamonov V.Yu., Ganiev S.R., Ismakov R.A., Kuznetsov Yu.S., Pustovgar A.P., Sultanov D.R., Shmirkov O.V. Experimental studies of wave action on the suspension of montmorillonite clay. Nanotehnologii v stroitel'stve $=$ Nanotechnologies in Construction. 2018, Vol. 10, no. 4, pp. 166-180. DOI: dx.doi.org/10.15828/20758545-2018-10-4-166-180. (In Russian). 


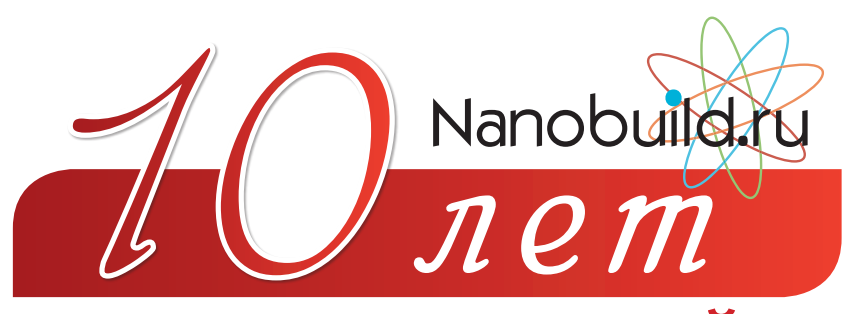

конкурс статей

уДК 622.244.4

Автор: АРТАМОНОВ Вадим Юрьевич, канд. техн. наук, ст. научн. сотрудник,

Институт машиноведения им. А.А. Благонравова Российской академии наук; ул. Бардина, д. 4 , Москва, Россия, 119334, e-mail: vartamonov@bk.ru;

Автор: ГАНИЕВ Станислав Ривнерович, канд. техн. наук, вед. научн. сотрудник,

Институт машиноведения им. А.А. Благонравова Российской академии наук; ул. Бардина, д. 4 , Москва, Россия, 119334;

Автор: ИСМАКОВ Рустэм Адипович, проф., д-р техн. наук, действительный член (академик)

РАEН, Почетный нефтяник, Почетный работник высшего профессионального образования

Российской Федерации, проректор по научной и инновационной работе, Уфимский

государственный нефтяной технический университет; ул. Космонавтов, 1, г. Уфа, Россия, 450062;

Автор: КУЗНЕЦОВ Юрий Степанович, проф., д-р техн. наук, зам. директора по научной работе, Институт машиноведения им. А.А. Благонравова Российской академии наук; ул. Бардина, д. 4 , Москва, Россия, 119334;

Автор: ПУСТОВГАР Андрей Петрович, канд. техн. наук, вед. научн. сотрудник,

Институт машиноведения им. А.А. Благонравова Российской академии наук; ул. Бардина, д. 4, Москва, Россия, 119334;

Автор: СУ ЛТАНОВ Данир Ризифович, канд. техн. наук, научн. сотрудник, Институт

машиноведения им. А.А. Благонравова Российской академии наук; ул. Бардина, д. 4, Москва, Россия, 119334, e-mail: sultanov.d.r@yandex.ru;

Автор: ШМЫРКОВ Олег Владимирович, канд. техн. наук, зав. лаборатории,

Институт машиноведения им. А.А. Благонравова Российской академии наук; ул. Бардина, д. 4, Москва, Россия, 119334

\section{ЭКСПЕРИМЕНТАЛЬНЫЕ ИССЛЕДОВАНИЯ ВОЛНОВОГО ВОЗДЕЙСТВИЯ НА СУСПЕНЗИЮ МОНТМОРИЛЛОНИТОВОЙ ГЛИНЫ}

АННОТАЦИЯ К СТАТЬЕ (АВТОРСКОЕ РЕЗЮME, РЕФЕРАT):

В работе приведены результаты комплексных исследований влияния волновых технологий на физико-механические свойства тонкодисперсных монтмориллонитовых суспензий в лабораторных условиях Научного Центра нелинейной волновой механики и технологии РАН (НЦ НВМТ ИМАШ РАН). 
Показано, что в результате волновой обработки проточными гидродинамическими генераторами вихревого типа с тангенциальными и радиальными каналами и генераторами плоского типа с цилиндрическими телами обтекания динамическое напряжение сдвига существенно увеличилось, количество частиц раствора размером 1-2 мкм выросло в 2,5 раза. Это означает, что волновая обработка глинистой суспензии приводит к повышению коллоидной фракции, а следовательно, и к повышению качества суспензии, к снижению расхода глинопорошка, а также к уменьшению в несколько раз времени приготовления по сравнению с традиционной технологией. Показано, что основной вклад в достижение высокой эффективности волновой обработки вносят нелинейные волновые и кавитационные процессы, протекающие в проточной части гидродинамических генераторов.

Ключевые слова: монтмориллонит, глинистая суспензия, волновые технологии, волновое поле, фильтрационно-емкостные свойства пласта, призабойная зона пласта, скорость фильтрации.

DOI: dx.doi.org/10.15828/2075-8545-2018-10-4-166-180

МАШИНОЧИТАЕМАЯ ИНФОРМАЦИЯ О СC-ЛИЦЕНЗИИ в МЕТАДАННЫХ СТАТЬИ (HTML-КОД):

$<$ a rel="license" href="http://creativecommons.org/licenses/by/4.0/" ><img alt="Creative Commons License" style="borderwidth:0" src="https://i.creativecommons.org/l/by/4.0/88x31.png" $/></ \mathrm{a}><$ br $/><$ span xmlns:dct="http://purl.org/dc/ terms/" href="http://purl.org/dc/dcmitype/Text" property="dct:title" rel="dct:type" $>$ Experimental studies of wave action on the suspension of montmorillonite clay $</$ span $>$ by $<$ a xmlns:cc $="$ http://creativecommons.org/ns\#" href $=$ "Nanotehnologii v stroitel'stve $=$ Nanotechnologies in Construction. 2018, Vol. 10, no. 4, pp. 166-180. DOI: dx.doi.org/10.15828/2075- 85452018-10-4-166-180" property="cc:attributionName" rel="cc:attributionURL">Artamonov V.Yu., Ganiev S.R., Ismakov R.A., Kuznetsov Yu.S., Pustovgar A.P., Sultanov D.R., Shmirkov O.V. </a $>$ is licensed under a $<$ a rel="license" href="http:// creativecommons.org/licenses/by/4.0/" $>$ Creative Commons Attribution 4.0 International License $</ \mathrm{a}>$. $<$ br $/>$ Based on a work at <a xmlns:dct="http://purl.org/dc/terms/" href=" http://nanobuild.ru/en_EN/nanobuild-4-2018/" rel="dct:source">

http://nanobuild.ru/en_EN/nanobuild-4-2018/ $</ \mathrm{a}>$. $<$ br $/>$ Permissions beyond the scope of this license may be available at $<$ a xmlns:cc="http://creativecommons.org/ns\#" href="vartamonov@bk.ru" rel="cc:morePermissions" $>$ vartamonov@bk.ru</a $>$.

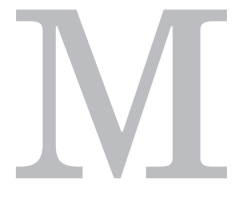

онтмориллонитовые глины - уникальный природный материал. Они находят применение в самых разных областях, от строительства глубоких скважин до пищевой промышленности и производства косметических средств. И все это благодаря таким их свойствам, как высокая гидрофильность и адсорбционная способность, катионообменные свойства, нетоксичность и др. Большинство этих 
свойств непосредственно зависит от степени дисперсности этих глин. Как известно, среди огромного разнообразия глинистых минералов именно монтмориллонит в наибольшей степени способен набухать в водной среде и диспергироваться самопроизвольно. При приготовлении суспензии из монтмориллонитовых глин, например, буровой промывочной жидкости достаточно простого механического или гидродинамического перемешивания их в пресной или слабоминерализованной воде. Но возможно ли кратно увеличить дисперсность глин и каким образом? Именно этот вопрос поставили мы перед собой в наших исследованиях, которые были проведены в Научном Центре нелинейной волновой механики и технологии РАН (НЦ НВМТ ИМАШ РАН).

Известно, что для диспергирования природных дисперсных материалов, таких как глина, барит, мел и др., применяются различного рода устройства, как правило, механические и гидравлические мешалки. Не всегда их работа достаточно эффективна. Для повышения качества и эффективности приготовления буровой промывочной жидкости предлагаются различные усовершенствования, например, гидравлическая камера со встречными потоками жидкости типа «струя в струю» или дезинтегратор со встречно вращающимися с высокой скоростью дисками. Такие устройства требуют больших затрат энергии и подводимой мощности. [1]

Нами были проведены исследования влияния волновой обработки водной монтмориллонитовой суспензии на ее физико-механические свойства: степень дисперсности и реологические показатели. Цель этих исследований заключалась в повышении эффективности приготовления и получения качественно иных характеристик монтмориллонитовых суспензий.

В задачи экспериментов входило:

- исследование эффективности волновых генераторов различных конструкций для диспергирования глинистой монтмориллонитовой суспензии и влияния волновой обработки на ее дисперсность и реологические свойства;

- определение оптимальных конструкций и режимов работы генераторов для эффективного приготовления буровых промывочных жидкостей.

Исследования проводили на гидродинамическом стенде, схема которого приведена на рис. 1. Для волновой обработки глинистой суспен- 


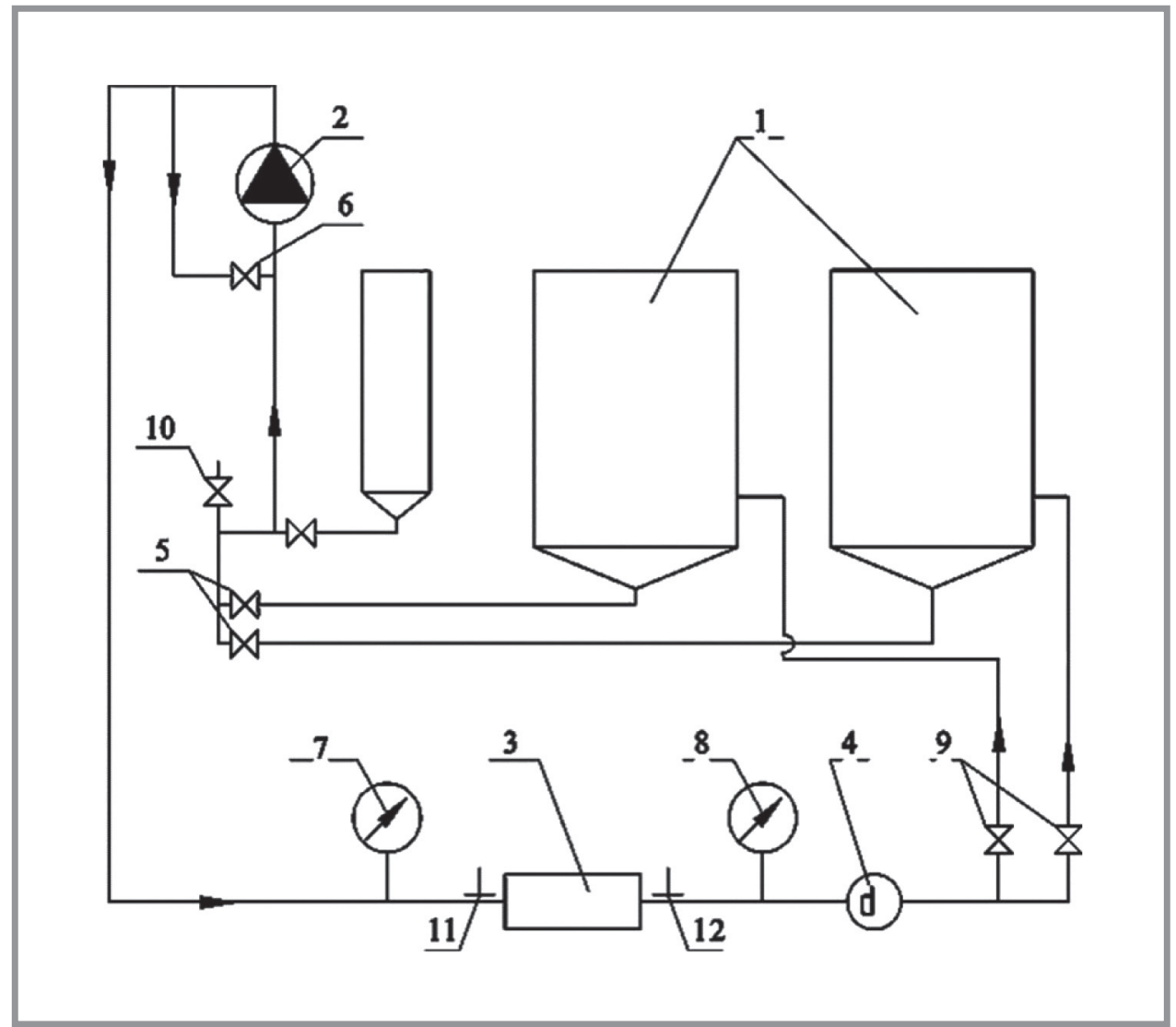

Рис. 1. Принципиальная схема гидродинамического стенда:

1 - емкости с жидкостью; 2 - насос; 3 - проточный генератор; 4 - расходомер;

5 - входные вентили; 6 - вентили рециркуляции насоса; 7 - манометр PBX;

8 - манометр РВЫХ; 9 - выходные вентили; 10 - дренаж; 11 - датчик температуры; 12 - датчик переменного давления

зии использовались экспериментальные волновые генераторы проточного типа с различной геометрией рабочей камеры. В этих генераторах, в плоских профилированных каналах которых установлены тела обтекания различной формы, так же, как и в камерах с тангенциальными каналами подачи рабочей жидкости, образуются вихревые высокотурбулентные отрывные потоки, а также обширные области развитой кавитации, возбуждающие мощные колебания и волны в обрабатываемых средах [2-4].

В качестве объекта исследований - материала для приготовления суспензии - использовали высококачественную бентонитовую глину Даш-Салахлинского месторождения Азербайджана. Этаглина содержит от 80 до 95\% монтмориллонита. Гранулометрическая характеристика 
суспензии этой глины, приготовленной с помощью высокоскоростной механической мешалки, приведена на рис. 2а. Распределение частиц суспензии по размерам было получено с помощью прибора FRITSCH ANALYSETTE 22 методом лазерной дифракции.

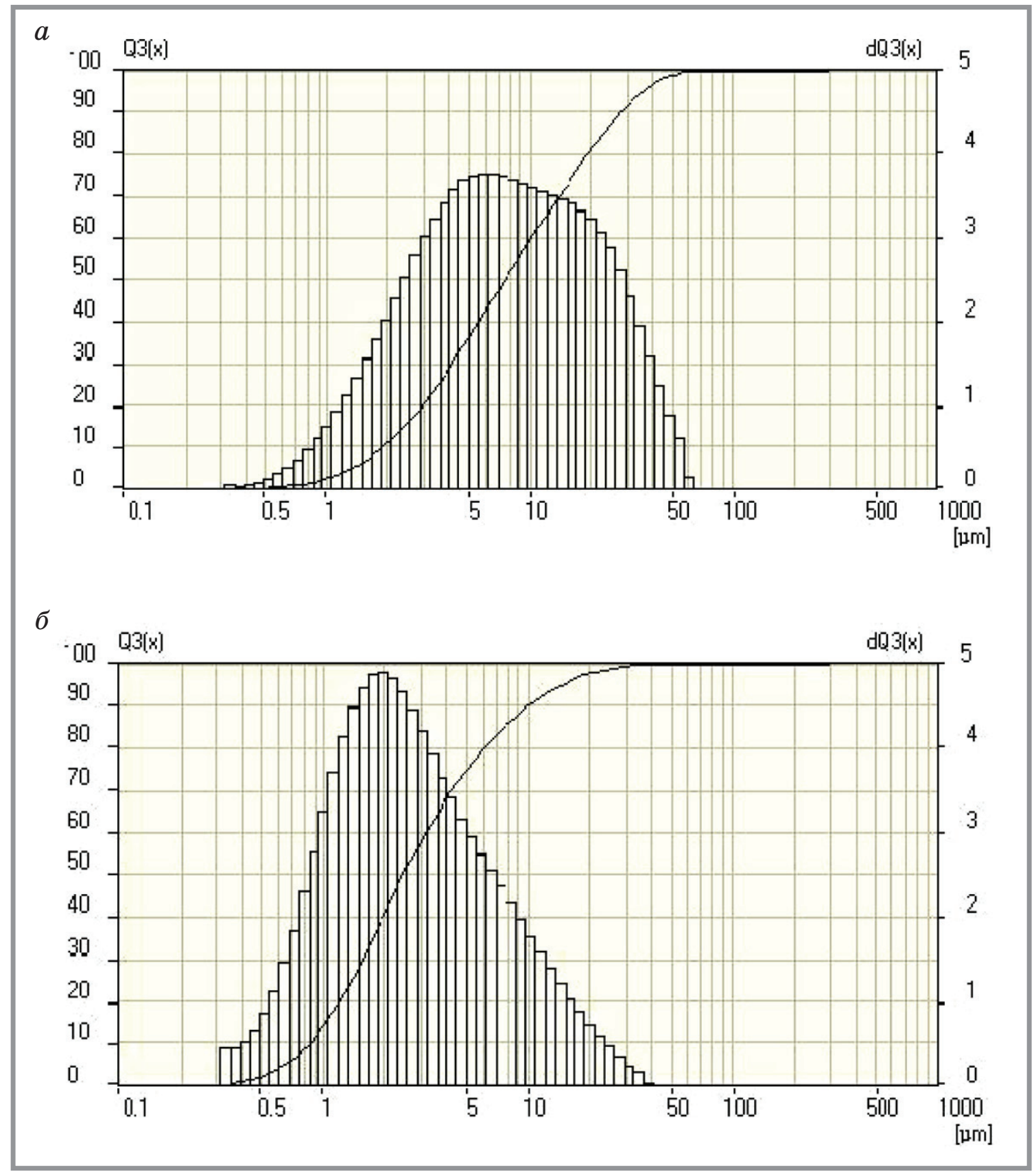

Рuc. 2. Гранулометрическая характеристика суспензии:

a - до волновой обработки, б - после волновой обработки 
Эксперименты проводили, подвергая суспензии монтмориллонита волновой обработке в проточных генераторах в различных режимах, находя оптимальный режим с помощью прибора-регистратора амплитудно-частотных характеристик (АЧХ) в потоке суспензии в генераторе. В результате волновой обработки степень дисперсности суспензии существенно возросла: средний (медианный) размер минеральных частиц монтмориллонита с 5-10 мкм уменьшился до 1-3 мкм (рис. 2б). Повышение дисперсности суспензии привело к значительному росту ее реологических характеристик (рис. 3). В свою очередь, высокая дисперсность суспензии позволяет получить хорошие технологические свойства буровой промывочной жидкости при меньшем расходе глинопорошка и химреагентов для ее обработки. Высокая дисперсность суспензии и меньший размер частиц твердой фазы способствуют созданию тонкого и малопроницаемого кольматационного экрана в стенке скважины, ограничению фильтрации дисперсионной среды бурового раствора в пласт, образованию тонкой и малопроницаемой фильтрационной корки, предупреждению осложнений в процессе бурения и подготовке ствола скважины к цементированию обсадных колонн. В целом, это повышает качество первичного и вторичного вскрытия и разобщения проницаемых пластов.

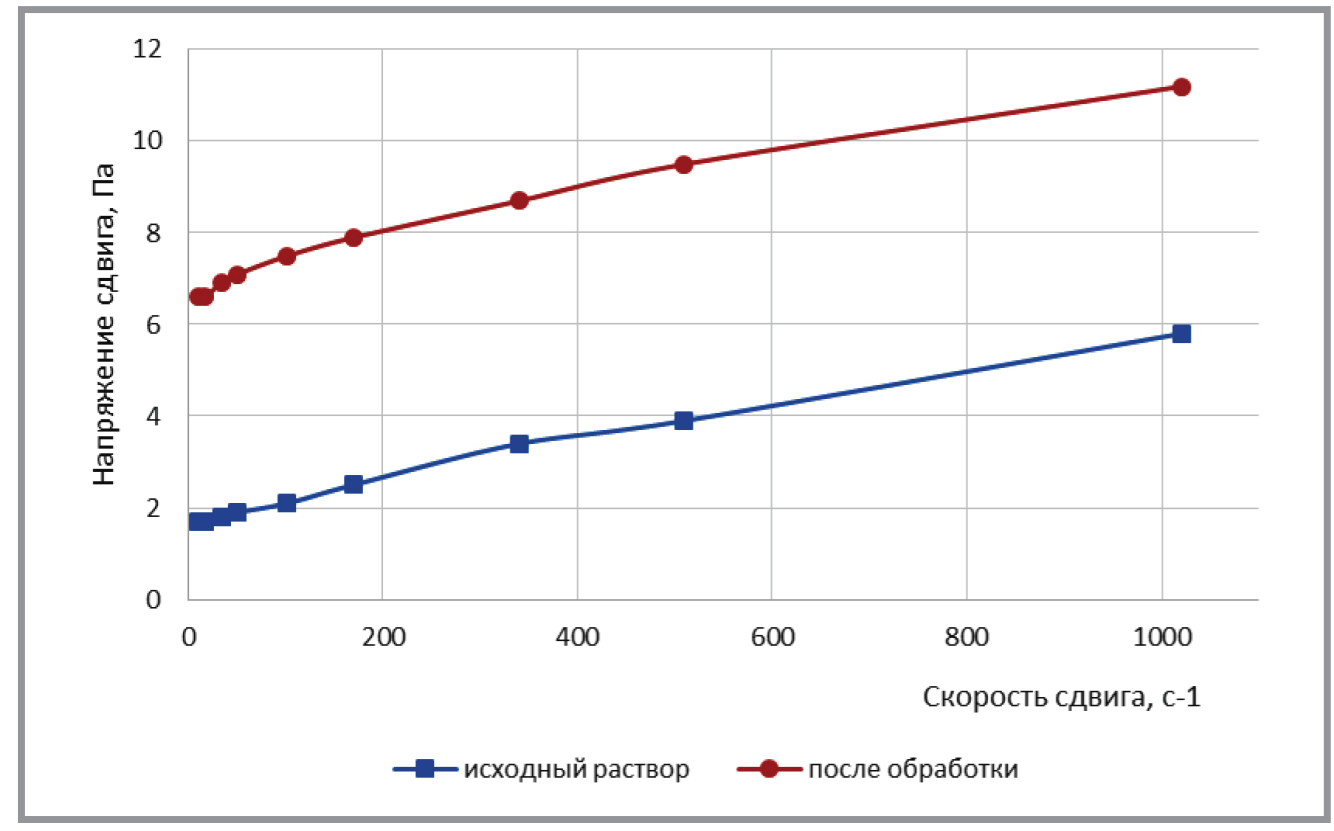

Рис. 3. Реологические кривые глинистой суспензии до и после обработки 
Получение высоких значений вязкости и динамического напряжения сдвига суспензии в результате волновой обработки в проточных генераторах в стендовых условиях позволяет сделать вывод о перспективности такой обработки буровых промывочных жидкостей для повышения их качества и снижения расхода материалов.

В промысловых условиях опытная волновая обработка глинистой суспензии с использованием полноразмерных генераторов конструкции НЦ НВМТ ИМАШ РАН была проведена в ноябре 2016 года.

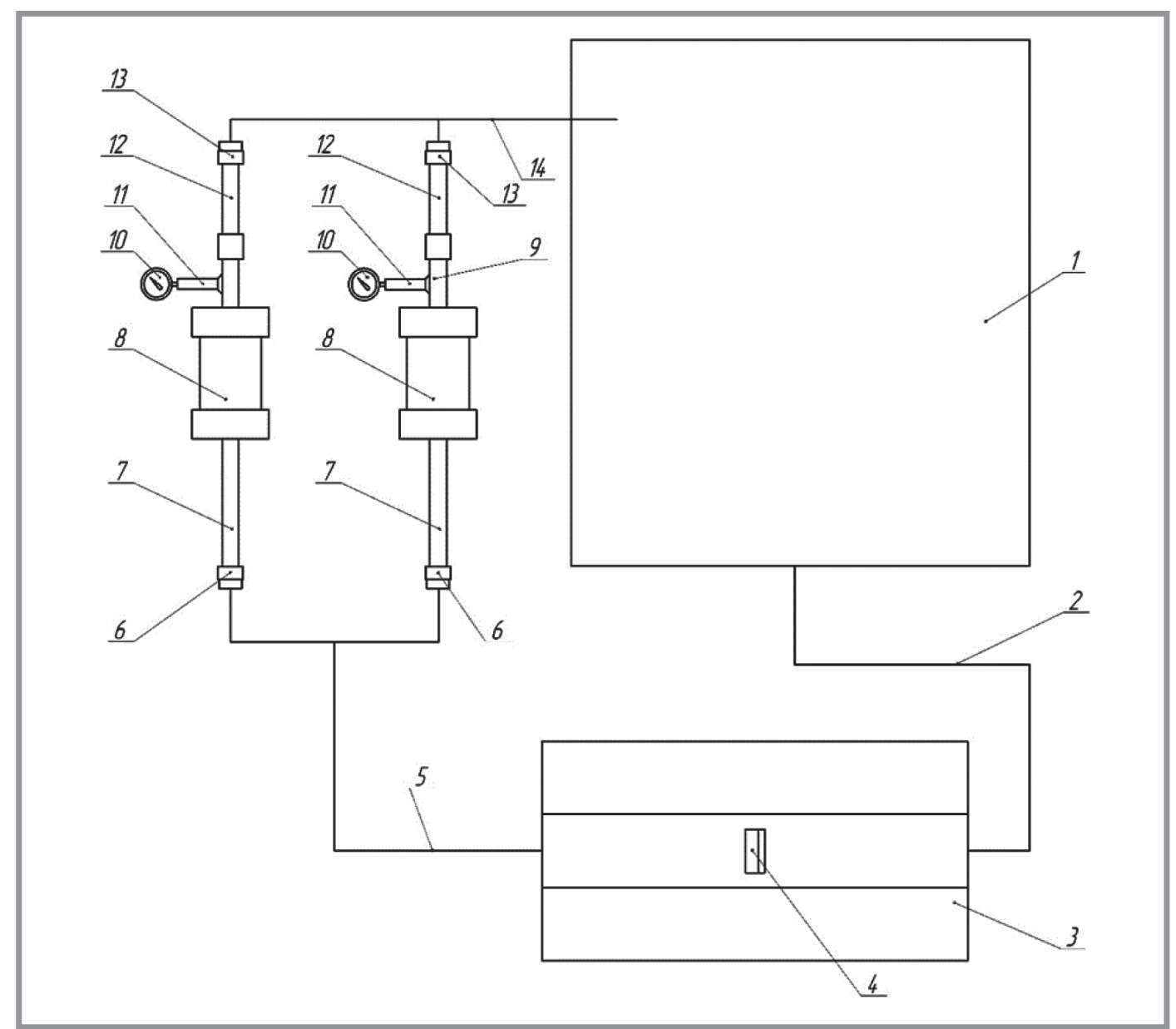

Рис. 4. Схема гидравлической обвязки проточного генератора в процессе приготовления глинистого бурового раствора:

1 - 50-ти кубовая емкость; 2 - линия всасывания насоса; 3 - буровой насос; 4 - манометр насоса; 5 - нагнетательная линия; 6 - быстросъемное соединение;

7 - патрубок (НКТ 60H/60H); 8 - генератор; 9 - переходник (HКТ 60H/60H);

10 - манометр; 11 - демпфер манометра; 12 - патрубок (НКТ 60H/60H);

13 - быстросъемное соединение; 14 - выкидная линия 
Технологическая схема процесса волновой обработки приведена на рис. 4.

В процессе работы волновых генераторов с телами обтекания производились отборы проб бурового раствора и их лабораторные исследования; результаты исследований приведены в табл. 1.

таблица 1

Технологические показатели бурового раствора до и после волновой обработки

\begin{tabular}{|l|c|c|c|c|}
\hline $\begin{array}{c}\text { Время работы } \\
\text { генератора }\end{array}$ & Усл. вяз., с & $\eta$, мПа*с & $\tau_{\mathbf{0}}$, дПа & $\begin{array}{c}\text { СНС 10с/10мин, } \\
\text { дПа }\end{array}$ \\
\hline $\begin{array}{l}\text { Раствор } \\
\text { до обработки }\end{array}$ & 19 & 7 & 23,9 & $38 / 71,8$ \\
\hline 15 мин. & 22 & 7 & 28,7 & $48 / 91$ \\
\hline 45 мин. & 24 & 6,5 & 38,3 & $67 / 119,7$ \\
\hline 60 мин. & 26 & 6,5 & 43,1 & $67 / 119,7$ \\
\hline
\end{tabular}

Результаты показали, что волновая обработка повысила условную вязкость и динамическое напряжение сдвига суспензии.

В процессе промысловых испытаний волнового генератора вихревого типа произвели приготовление $50 \mathrm{~m}^{3}$ глинистой суспензии. Результаты лабораторных исследований обрабатываемого раствора приведены в табл. 2.

Таблица 2

Технологические показатели бурового раствора до и после волновой обработки

\begin{tabular}{|l|c|c|c|c|}
\hline $\begin{array}{c}\text { Время работы } \\
\text { генератора }\end{array}$ & Усл. вяз., с & $\eta$, мПа ${ }^{*} \mathbf{c}$ & $\tau_{\mathbf{0}}$, дПа & $\begin{array}{c}\text { СНС 10с/10мин, } \\
\text { дПа }\end{array}$ \\
\hline $\begin{array}{l}\text { Раствор } \\
\text { до обработки }\end{array}$ & 20 & 6 & 19 & $43 / 67$ \\
\hline 30 мин. & - & 5 & 67 & $90,9 / 139$ \\
\hline 60 мин. & 25,4 & 3,5 & 81,4 & $101 / 153$ \\
\hline
\end{tabular}


Эти данные подтвердили влияние волновой обработки на повышение дисперсности суспензии.

\section{Выводы}

Исследования волнового диспергирования монтмориллонитовых суспензий в стендовых условиях НЦ НВМТ ИМАШ РАН с помощью проточных волновых генераторов показали их эффективность и значительное преимущество перед известными традиционными способами диспергирования. Дисперсность монтмориллонитовой суспензии была существенно повышена.

В результате проведенных экспериментов и промысловых испытаний волновых генераторов были существенно улучшены реологические характеристики глинистой суспензии, повышено качество приготовленной промывочной жидкости в целом.

В результате экспериментальных и опытно-промысловых работ были определены оптимальные конструкции и режимы работы генераторов для эффективного приготовления буровых промывочных жидкостей.

\section{Библиографический список:}

1. Гайдаров M., Кравиов C.A. Дезинтеграторная технология приготовления буровых растворов и технологических жидкостей // Строительство нефтяных и газовых скважин на суше и на море. - 2007. - № 10. - С. 29-33.

2. Ганиев Р.Ф. Волновые машины и технологии (введение в волновую технологию). - М.: Науч.-изд. центр РХД, 2008. - 192 с.

3. Ганиев Р.Ф., Украинский Л.Е. Нелинейная волновая механика и технологии. - М: Науч.-изд. центр РХД, 2008. - 712 с.

4. Ганиев Р.Ф. Нелинейные резонансы и катастрофы. Надежность, безопасность и бесшумность. - М.: Науч.-изд. центр РХД, 2013. - 592 с.

5. Арталонов В.Ю., Ганиев С.Р., Кузнецов Ю.С., Пустовгар А.П., Султанов Д.Р., Шмырков О.В. Волновая обработка малоглинистых суспензий // Колебания и волны в механических системах. Материалы Международной научной конференции. - 2017. C. $56-57$. 
6. Арталонов В.Ю., Аржанов А.Ф., Кузнецов Ю.С., Кузнецов Р.Ю., Султанов Д.Р., Шульгина А.П. Технология «щадящей» кольматации в процессе бурения // Колебания и волны в механических системах: Материалы Международной научной конференции. - 2017. - С. 61-63.

7. Урланчеев В.И., Овчинников В.П., Ганиев С.Р., Кузнецов Ю.С., Султанов Д.Р., Шакиров P.A. Применение дезинтеграторной технологии // Колебания и волны в механических системах: Материалы Международной научной конференции. - 2017. C. $79-80$.

8. Арталонов В.Ю., Пустовгар А.П., Султанов Д.Р., Кошелев А.Т., Кузнеиов Ю.С., Ганиев C.P. Волновая технология приготовления буровой промывочной жидкости // Строительство нефтяных и газовых скважин на суше и на море. -2017 . - № 11. C. 31-34.

9. Арталонов В.Ю., Шалов Н.А., Султанов Д.Р. Использование волновых процессов в обработке многофазных растворов // Машины, технологии и материалы для современного машиностроения: сборник тезисов докладов международной научной конференции. - Под ред. академика Р.Ф. Ганиева. - 2013. - С. 142.

10. Рахматуллина Г.В., Асрандияров Л.Х., Ислаков Р.А., Ниглатуллин В.Р., Ниглатуллин И.Р., Рахлатуллин В.Р., Заляев О.А. Изучение граничных смазочных слоев буровых промывочных сред // Трибология и надежность: сборник трудов XIII Международной научной конференции. - 2013. - С. 110-112.

11. Ислаков Р.А., Малаева О.Г., Конесев В.Г., Вязниковиев С.Ф., Матюшин В.П., Конесев Г.В. Исследование кинетических и коркообразующих свойств растворов для бурения скважин при строительстве трубопроводов и разработке месторождений углеводородов // Нефтегазовое дело. - 2011. - № 6. - С. 82-89.

12. Abrams A. Mud design to minimize rock impairment due to particle invasion. - J. Petr. Techn., may 1977, vol. 29, № 5, pp. 586-592.

13. Арталонов В.Ю. Разработка физико-химических методов кольматации коллекторов для повышения качества их вскрытия: дисс. на соискание ученой степени канд. техн. наук. - Тюмень: Тюменский государственный нефтегазовый университет, 2001. $-167 \mathrm{c}$.

14. Овчинников В.П., Агзамов Ф.А., Акбулатов Т.О., Аксенова Н.А., Анашкина А.Е., Герасилов Д.С., Гречин Е.Г., Грошева Т.В., Двойников М.В., Закиров Н.Н., Ислаков Р.А., Клещенко И.И., Конесев Г.В., Кузнецов В.Г., Кулябин Г.А., Курбанов Я.М., Кустышев А.В., Левинсон Л.М., Маковский Ю.С., Овчинников П.В. и др. Технология бурения нефтяных и газовых скважин. Учебник для студентов вузов в 5 томах. - Тюмень, 2017.

15. Макарова И.И. Исследование и разработка технологий, обеспечивающих сохранение природной проницаемости продуктивных пластов: дисс. на соискание ученой степени канд. техн. наук. - М.: Российская Академия Наук, 2013. - 148 с.

16. Игнатьев А.В., Кузнеиов Ю.С., Украинский Л.Е. Теоретические аспекты использования явления группирования частиц в волновом поле для кольматации пористых сред // Нефтегазовое дело. - 2010. - № 2. - URL: http://www.ogbus.ru/authors/ Ignatiev/Ignatiev_1.pdf 
17. Коротаев Ю.П. Расчет проникновения глинистого раствора в пласт / Ю.П. Коротаев, М.И. Швидлер // Газовая промышленность. - 1971. - № 8. - С. 1-2.

18. Поляков В.Н. Вяхирев В.И. Ипполитов В.В. Системные решения технологических проблем строительства скважин. - М.: ООО «Недра-Бизнесцентр», 2003. - 240с.

19. Черных В.А. Гидромеханика нефтегазодобычи. - М.: ООО «ВНИИГАЗ», 2001. - 277 с.

20. Шехтлан Ю.М. Фильтрация малоконцентрированных суспензий. - М.: АН СССР, 1961. $-212 \mathrm{c}$.

УВАЖАЕМЫЕ КОЛЛЕГИ!

ПРИ ИСПОЛЬЗОВАНИИ МАТЕРИАЛА ДАННОЙ СТАТЬИ

ПРОСИМ ДЕЛАТЬ БИБЛИОГРАФИЧЕСКУЮ ССЫЛКУ НА НЕЁ:

Арталонов В.Ю., Ганиев С.Р., Ислаков Р.А., Кузнецов Ю.С., Пустовгар А.П., Султанов Д.Р., Шлырков О.В. Экспериментальные исследования волнового воздействия на суспензию монтмориллонитовой глины // Нанотехнологии в строительстве. - 2018. - Том 10, № 4. - C. 166-180. - DOI: dx.doi. org /10.15828/2075-8545-2018-10-4-166-180.

\section{Dear Colleagues!}

THE REFERENCE TO THIS PAPER HAS THE FOLLOWING CITATION FORMAT:

Artamonov V.Yu., Ganiev S.R., Ismakov R.A., Kuznetsov Yu.S., Pustovgar A.P., Sultanov D.R., Shmirkov O.V. Experimental studies of wave action on the suspension of montmorillonite clay. Nanotehnologii v stroitel'stve $=$ Nanotechnologies in Construction. 2018, Vol. 10, no. 4, pp. 166-180. DOI: dx.doi.org/10.15828/20758545-2018-10-4-166-180. (In Russian). 